Supplement of SOIL, 2, 13-23, 2016

http://www.soil-journal.net/2/13/2016/

doi:10.5194/soil-2-13-2016-supplement

(C) Author(s) 2016. CC Attribution 3.0 License.

(c) (i)

Supplement of

\title{
On the rebound: soil organic carbon stocks can bounce back to near forest levels when agroforests replace agriculture in southern India
}

H. C. Hombegowda et al.

Correspondence to: H. C. Hombegowda (hombegowdaars@gmail.com)

The copyright of individual parts of the supplement might differ from the CC-BY 3.0 licence. 

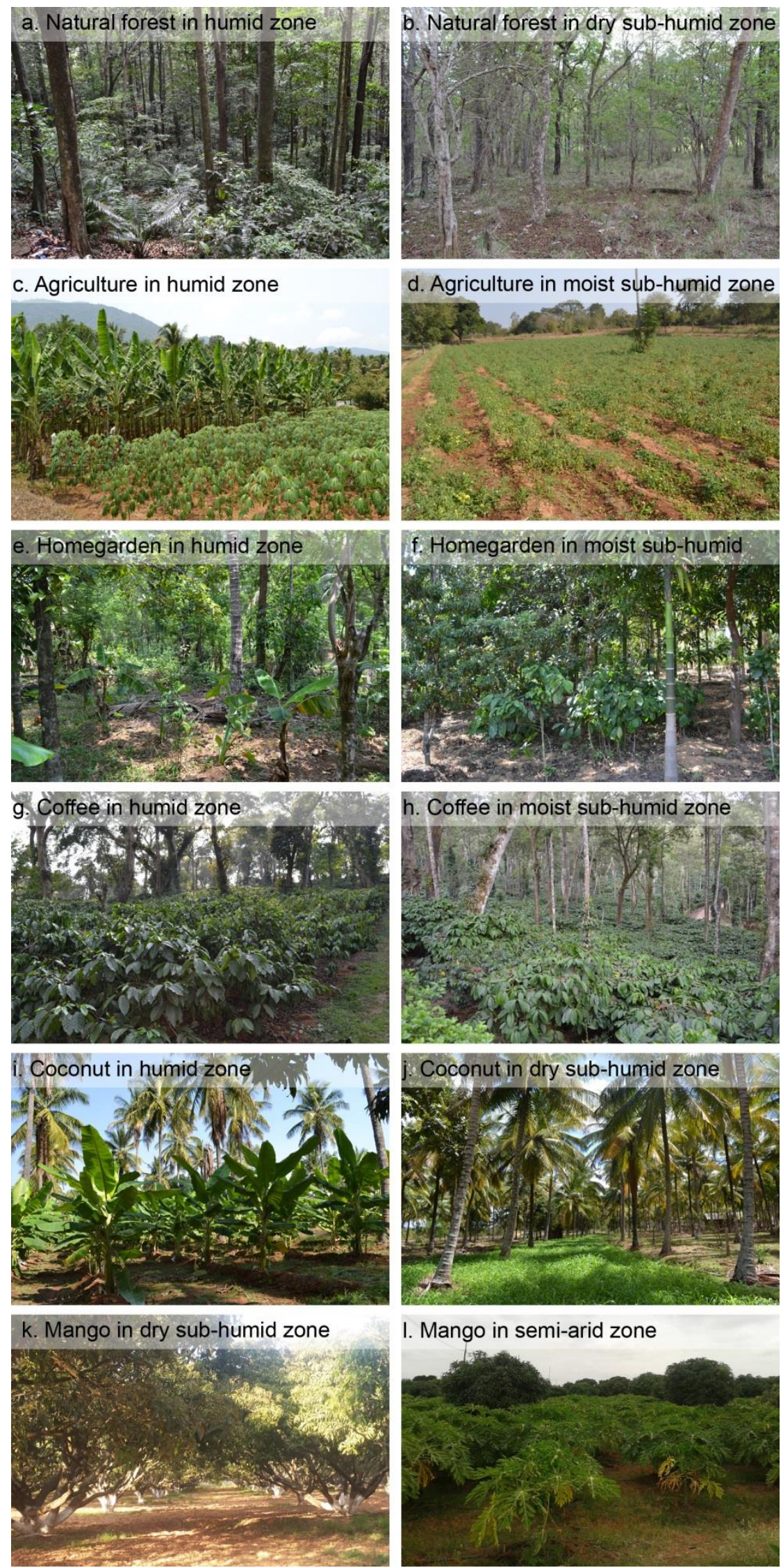

Figure S1. Photos of the six land use types investigated in two climatic zones. 


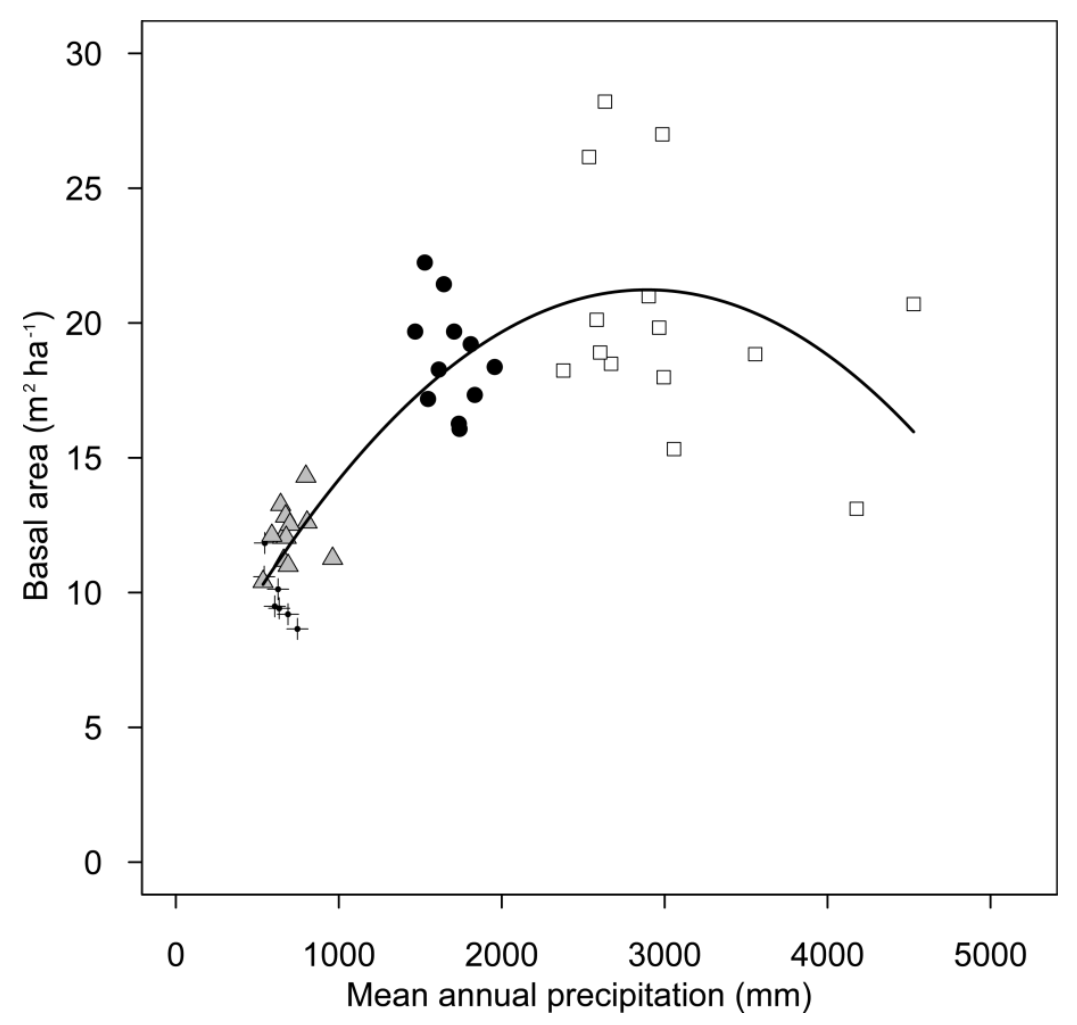

Figure S2. Scatterplot showing the relationship between basal area $\left(\mathrm{m}^{2} \mathrm{ha}^{-1}\right)$ and MAP $(\mathrm{mm})$ across humid $(\square)$, moist-sub-humid $(\bullet)$, dry sub-humid $(\triangle)$ and semi-arid (+) climate zones. 

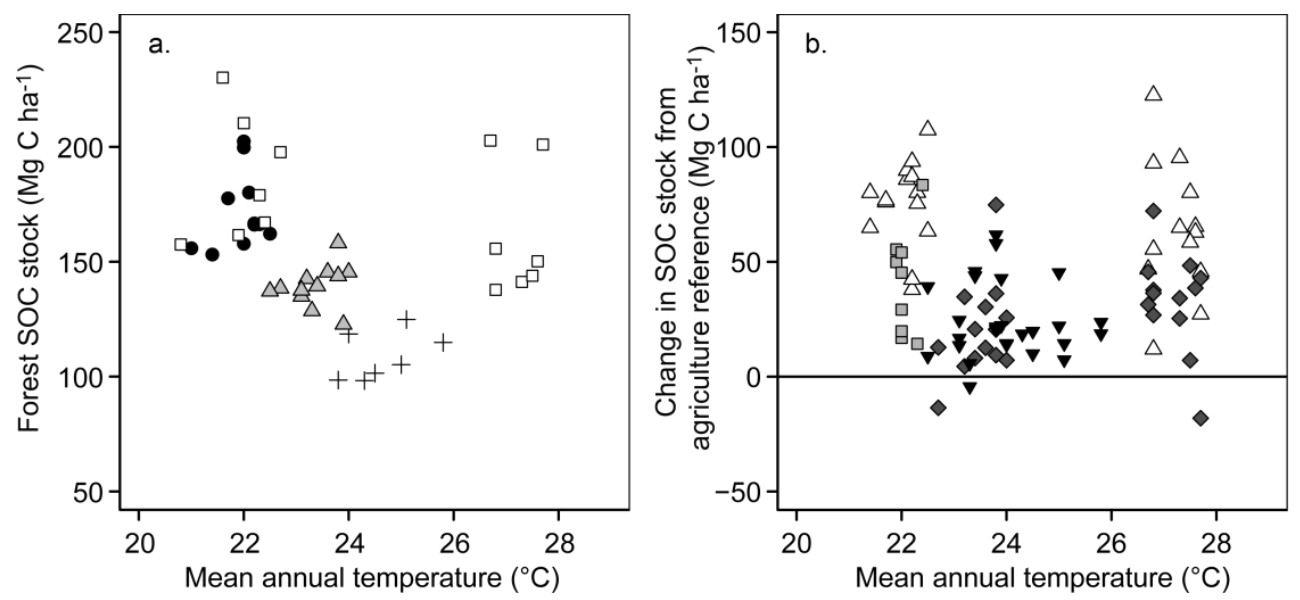

Figure S3. Scatterplots showing the relationship (or lack thereof) between MAT $\left({ }^{\circ} \mathrm{C}\right)$ and $(\mathrm{a})$ forest SOC stocks across humid $(\square)$, moist-sub-humid $(\bullet)$, dry sub-humid $(\triangle)$ and semi-arid (+) climate zones and (b) changes in SOC stocks in in homegardens $(\triangle)$, coffee $(\square)$, coconut $(\diamond)$ and mango $(\nabla)$ AFS. 


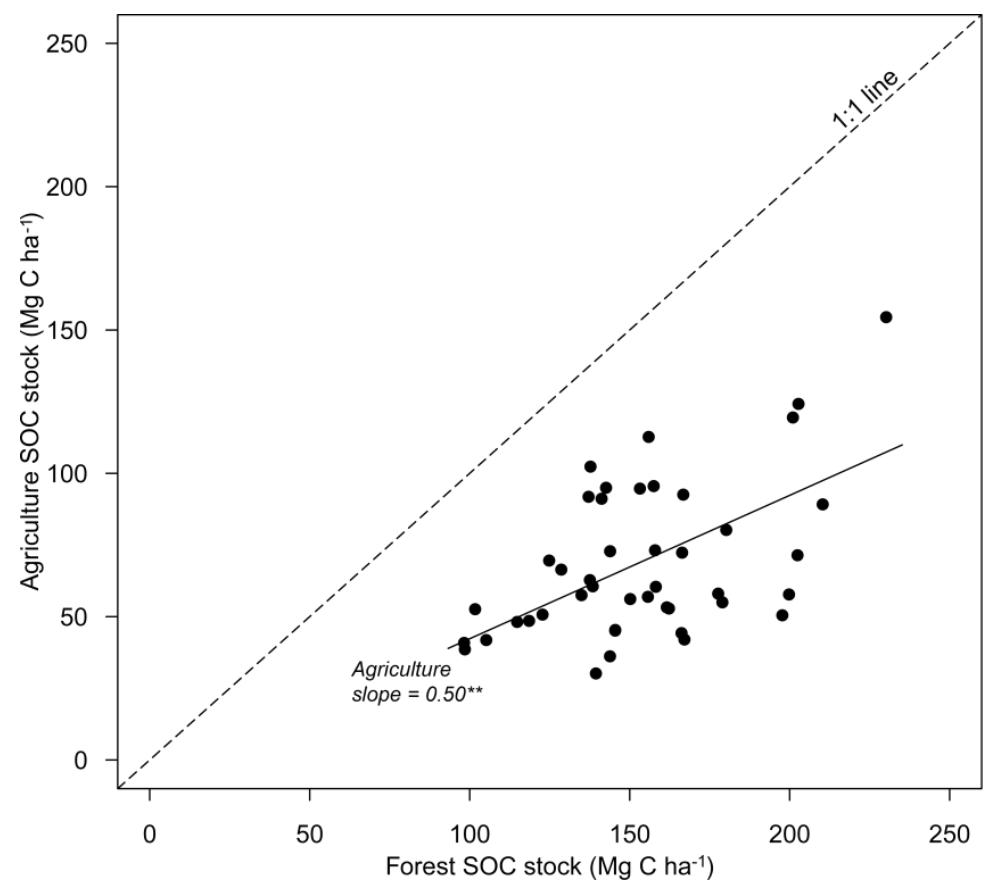

Figure S4. a) Agriculture SOC stocks (0) in comparison to forest reference SOC stock in the $100 \mathrm{~cm}$ soil profile. The slope of the linear regression $(\mathrm{m})$ that differed significantly from one highlight an uneven response of carbon loss or gain as affected by the initial SOC stocks. The stars, ${ }^{* *}$ indicates that the linear regression slope is significantly different from one (P $<0.01)$. 


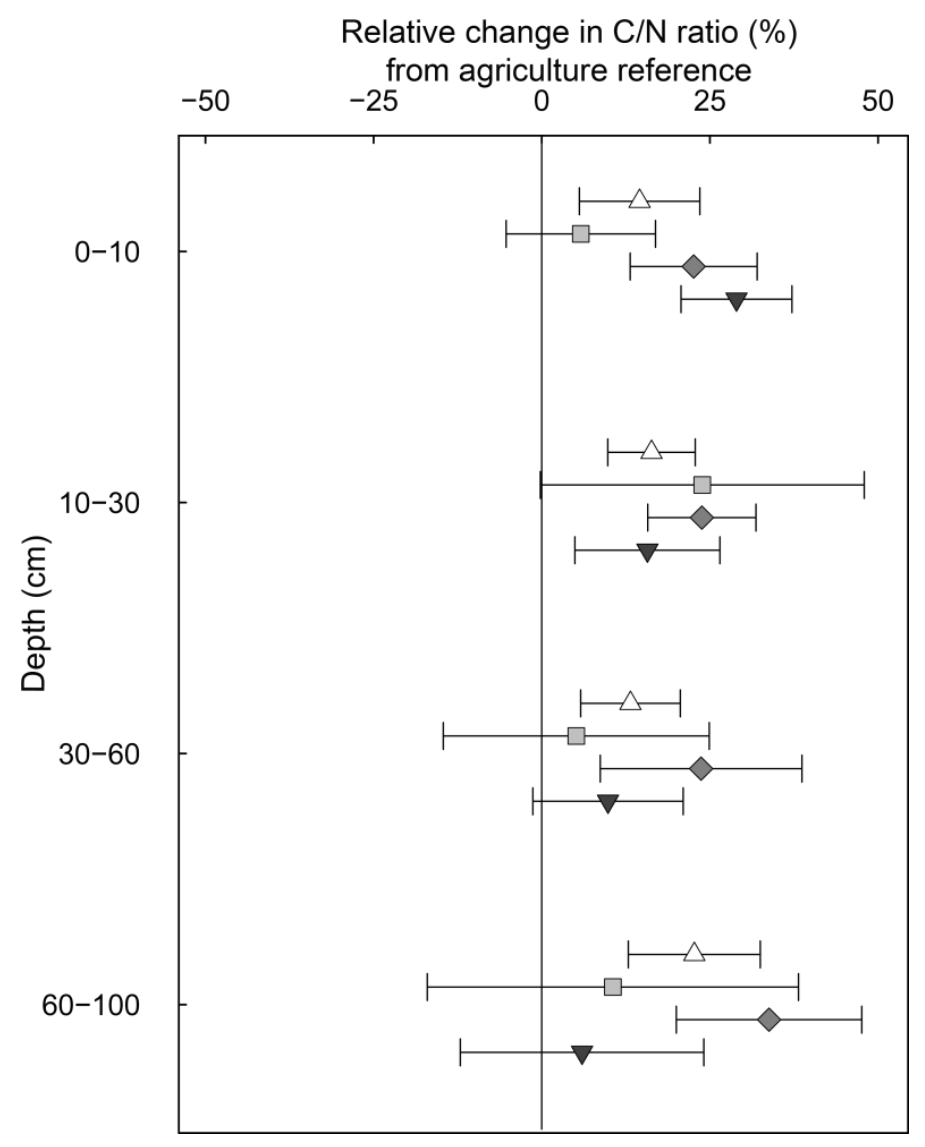

Figure S5. Relative change in $\mathrm{C} / \mathrm{N}$ ratio in the 1-m soil profile from agriculture to agroforestry systems (homegarden $(\triangle ; n=27)$, coffee $(\square ; n=9)$ coconut $(\diamond ; n=28)$ and mango $(\nabla ; n=28)$. Error bars indicate the 95\% confidence intervals based on the Student's T distribution. 